\title{
Brain somatostatin concentrations do not decrease in progressive supranuclear palsy
}

\author{
J EPELBAUM, F JAVOY-AGID, ${ }^{*}$ E HIRSCH,${ }^{*}$ J J HAUW, $\dagger$ C KORDON, \\ S KRANTIC, Y AGID*
}

From the Laboratoire de Médecine Expérimentale U. 159, INSERM*, 2 ter rue d'Alesia, and Laboratoire de Neuropathologie Escourolle $\dagger$ Hôpital de la Salpêtrière, Paris, France

SUMMARY The concentrations of somatostatin and choline acetyl transferase (CAT) were measured in nine brains from patients with progressive supranuclear palsy (PSP) and compared with those obtained from 19 matched control brains. In PSP, CAT activity was reduced in the caudate nucleus and limbic areas (amygdala, hippocampus and cingulate cortex) but was not different from controls in neocortical areas (frontal and temporal). Somatostatin concentrations were not different from controls in any region tested. In contrast to Alzheimer's disease and Parkinson's disease, intellectual deterioration in PSP is not associated with a deficit in neocortical somatostatin and CAT levels.

Senile dementia of Alzheimer type (SDAT) is associated with cortical neuronal loss, histopathological stigmata such as neurofibrillary tangles and neuritic plaques, ${ }^{1}$ and decrease in somatostatin levels, ${ }^{2}$ a peptide which is known to be contained in intrinsic neurons. This model of so-called "cortical dementia" 3 is also associated with lesions of subcortical areas particularly of the substantia innominata from which originates the cholinergic innervation of the cortex. Degeneration of this subcortico-cortical neurotransmitter system may contribute to intellectual impairment in patients. ${ }^{4}$ Parkinson's disease mainly characterised by marked cell loss in the substantia nigra shares clinical, anatomical and biochemical features with SDAT:the subcortico-cortical cholinergic system is affected ${ }^{5}$ and the severity of the cholinergic deficit has been related to intellectual deterioration. ${ }^{56}$ Neurons in the cerebral cortex probably degenerate in the demented Parkinsonians since histopathological

Address for reprint requests: J Epelbaum, U. 159 INSERM, 2 ter rue d'Alésia, 75014 Paris, France.

Received 23 January 1987 and in revised form 3 April 1987. Accepted 16 April 1987 changes of Alzheimer's type can be observed ${ }^{1}$ and concentrations of somatostatin decrease in the frontal cortex and hippocampus. ${ }^{7}$

The aim of the present study was to test whether dementia is also associated with cortical cholinergic and somatostatinergic deficits in progressive supranuclear palsy (PSP), a paradigm for "subcortical dementia" (see 8 for review). In PSP, the massive neuronal degeneration in the basal ganglia and upper brainstem contrasts with the absence of gross lesions in the cerebral cortex. ${ }^{8}$ The severe frontal lobe-like syndrome has been attributed to "frontal deafferentation" through interruption of the basal ganglia output towards the frontal area. ${ }^{8}$ In contrast to SDAT and Parkinson's disease, the subcorticocortical dopaminergic, ${ }^{9}$ noradrenergic, serotoninergic, ${ }^{10}$ and cholinergic ${ }^{910}$ systems seem mainly spared.

\section{Material and methods}

Nineteen control brains from subjects with no known neurological or psychiatric diseases and nine brains from patients with clinically and histopathologically diagnosed PSP $^{9}$ were examined. Intellectual deterioration was diagnosed on the basis of retrospective analysis of case histories and refers to a constellation of symptoms (slowness of ide- 
ation, inertia, defective motivation, difficulty in changing intellectual strategy). The control and the pathological population were matched with respect to age (mean \pm SEM: control $=73.9 \pm 2 \cdot 1 ;$ PSP $=68 \cdot 0 \pm 2 \cdot 4$ ) and postmortem delay (mean \pm SEM: control $=8.3 \pm 1 \cdot 4$; PSP $=13.0 \pm$ $1.5)$ in tissue handling. ${ }^{9}$

Within less than 2 hours after necropsy, the brain hemisphere was stored at $-70^{\circ} \mathrm{C}$ until dissection. Brain structures were dissected from tissue sections without thawing and then pulverised on dry ice. Somatostatin levels were measured by radioimmunoassay, ${ }^{7}$ and choline acetyltransferase activity by a radioenzymatic method ${ }^{5}$ on an aliquot of frozen tissue as previously described. Statistical significance was determined by Student's $t$ test.

\section{Results}

Cholineacetyltransferase (CAT) activity was reduced in the caudate nucleus and in limbic areas such as amygdala, hippocampus and cingulate cortex of patients with PSP when compared with controls (table). In the neocortical areas (frontal and temporal) CAT activity was not significantly affected. Somatostatin concentrations in the PSP brains were not significantly different from controls in the various areas investigated (table).

\section{Discussion}

In the striatum of PSP patients, the subnormal CAT activity confirms the observations of Ruberg et $\mathrm{al}^{9}$ though it differs from the normal activity reported by Kish et al. ${ }^{10}$ The data emphasise a degeneration of intrastriatal cholinergic neurons and are compatible with the neuropathological evidence that PSP is associated with a neuronal loss in the striatum (see 1 for review). CAT activity investigated in other brain areas was decreased compared to control values in limbic (amygdala, hippocampus, cingulate cortex) but not in neocortical areas (table). By reference to the organisation of the basal forebrain cholinergic cells, the major source of forebrain cholinergic afferents in animal brain, ${ }^{11}$ the data may indicate that some groups of cholinergic neurons are affected but others are essentially spared in PSP. The $50 \%$ reduction in CAT activity in the hippocampus of PSP patients suggests that the septohippocampal cholinergic pathway is most likely damaged. On the contrary, the cholinergic afferents to the neocortex which originate in the substantia innominata seem moderately, if at all, affected (table) ${ }^{910}$ since the enzyme activity was not markedly different from control in frontal and temporal cortex (table). This observation is in accordance with the moderate neuronal loss in the substantia innominata of PSP patients. ${ }^{12}$ The cholinergic deficit in the hippocampus and limbic regions of the cortex may account for some aspects of intellectual deterioration since it is also observed in SDAT patients ${ }^{4}$ or demented Parkinsonians. ${ }^{5}$ However, at difference with SDAT or Parkinson's disease, intellectual deterioration in PSP does not seem to be associated to a neocortical cholinergic deficiency.

Somatostatin concentrations were not significantly different from control values in the cortical areas investigated in brains from PSP patients (table) suggesting that cortical somatostatin containing neurons considered to be intrinsic systems are not affected. These data are compatible with the histopathological reports on the absence of severe lesions in the cerebral cortex of patients. ${ }^{8}$ In addition, the somatostatin innervation of the striatum, hippocampus and amygdala seems preserved. Thus, PSP is not associated with an alteration of the cortical (or subcortical) somatostatin systems investigated, an observation in sharp contrast with SDAT and PD where a dementiarelated deficiency in cortical somatostatin has been established. $^{27}$

In PSP, not only the innominato-cortical cholinergic pathway, but also the mesocortical dopaminergic, ${ }^{9}$ the coeruleo-cortical noradrenergic ${ }^{810}$ and the raphe-cortical serotoninergic ${ }^{810}$ pathways seem to be intact. The data emphasise that the severe frontal lobe-like symptoms which characterise PSP from a neuropsychological view are not the consequence of a severe dysfunction of the main ascending subcorticocortical pathways. ${ }^{8}$ Since the major neuronal loss

Table Somostatin levels and CAT activity in brain regions of PSP patients

\begin{tabular}{|c|c|c|c|c|c|c|}
\hline Somatostatin & Caudate & Amygdala & Hippocampus & Cingulate cortex & Frontal cortex & Temporal cortex \\
\hline $\begin{array}{l}\text { Somatostatin } \\
\text { Control } \\
\text { PSP }\end{array}$ & $\begin{array}{l}\text { g tissue } \\
56.4 \pm 8 \cdot 7 \\
42.2 \pm 3 \cdot 8\end{array}$ & $\begin{array}{l}148 \cdot 3 \pm 21 \cdot 2 \\
144 \cdot 1 \pm 14 \cdot 2\end{array}$ & $\begin{array}{l}33 \cdot 3 \pm 3 \cdot 7 \\
33 \cdot 5 \pm 3 \cdot 4\end{array}$ & $\begin{array}{l}57 \cdot 5 \pm 4 \cdot 5 \\
57 \cdot 8 \pm 5 \cdot 3\end{array}$ & $\begin{array}{l}36 \cdot 5 \pm 3.9 \\
34.4 \pm 2.5\end{array}$ & $\begin{array}{l}29 \cdot 3 \pm 3 \cdot 7 \\
34 \cdot 4 \pm 2 \cdot 5\end{array}$ \\
\hline $\begin{array}{l}\text { CAT } n m / h / m \\
\text { Control } \\
\text { PSP }\end{array}$ & $\begin{array}{l}44 \cdot 3 \pm 4 \cdot 1 \\
28 \cdot 5 \pm 3 \cdot 8^{*}\end{array}$ & $\begin{aligned} & 12.2 \pm .9 \\
& 7.6 \pm 1.4^{*}\end{aligned}$ & $\begin{array}{l}8 \cdot 5 \pm 0 \cdot 8 \\
4 \cdot 6 \pm 0 \cdot 7 *\end{array}$ & $\begin{array}{l}4 \cdot 2 \pm 0 \cdot 2 \\
2 \cdot 7 \pm 0 \cdot 3^{*}\end{array}$ & $\begin{array}{l}2.1 \pm 0.1 \\
1.8 \pm 0.3\end{array}$ & $\begin{array}{l}2.0 \pm 0.1 \\
2.1 \pm 0.3\end{array}$ \\
\hline
\end{tabular}

Frontal, temporal and cingulate cortex refer to Brodmann's areas, 9, 20 and 24, respectively CAT activity and Somatostatin concentrations were estimated in 9 PSP and 19 control brains. Data are the mean \pm standard error of the mean (SEM).

${ }^{*} \mathrm{p}<0.05$ statistically significant when compared with controls. 
affects the output pathways of the basal ganglia (pallidum, substantia nigra, dentate nucleus thalamus) (see 8 for review) intellectual deterioration in PSP could rather result from disruption in the control of cortical activity originating in these structures.

\section{References}

1 Boller F, Mizutani T, Roessmann U, Gambetti P. Parkinson's disease, dementia and Alzheimer disease: clinico pathological correlations. Ann Neurol 1980;7:329-55.

2 Davies P. An update on the neurochemistry of Alzheimer's disease. In: Mayeux R, Rosen WG, eds. The Dementias. New York: Raven Press, 1983:75-86.

3 Benson DF. Subcortical dementia: a clinical approach. In: Mayeux R, Rosen WG, eds. The Dementias. New York: Raven Press, 1983:185-94.

4 Perry EK, Tomlinson BE, Blessed G, Bergmann $\mathrm{K}$, Gibson PH, Perry RH. Correlation of cholinergic abnormalities with senile plaques and mental test scores in senile dementia. Br Med J 1978;2:1457-9.

5 Dubois B, Ruberg M, Javoy-Agid F, Ploska A, Agid Y. A subcortico-cortical cholinergic system is affected in Parkinson's disease. Brain Res 1983;288:213-8.

6 Perry EK, Curtis M, Dick DJ, et al. Cholinergic cor- relates of cognitive impairment in Parkinson's disease: comparisons with Alzheimer's disease. J Neurol Neurosurg Psychiatry 1985;48:413-21.

7 Epelbaum J, Ruberg M, Moyse E, Javoy-Agid F, Dubois B, Agid Y. Somatostatin and dementia in Parkinson's disease. Brain Res 1983;278:376-9.

8 Agid Y, Javoy-Agid F, Ruberg M, Pillon B, et al. Progressive supranuclear palsy: anatomo-clinical and biochemical considerations. In: Yahr MD, Bergmann $\mathrm{KJ}$, eds. Advances in Neurology. Vol 45. New York: Raven Press, 1986:191-206.

9 Ruberg M, Javoy-Agid F, Hirsch E, et al. Dopaminergic and cholinergic lesions in progressive supranuclear palsy. Ann Neurol 1985;18:523-9.

10 Kish SJ, Chang LJ, Mirchandani L, Shannak K, Hornykiewicz O. Progressive supranuclear palsy: relationship between extrapyramidal disturbances, dementia and brain neurotransmitter markers. Ann Neurol 1985;18:530-6.

11 Wainer BH, Levey AI, Mufson EJ, Mesulam MM. Cholinergic systems in mammalian brain identified with antibodies against choline acetyltransferase. Neurochem Int 1984;6:163-82.

12 Arendt T, Bigl V, Arendt A, Tennstedt. Loss of neurons in the nucleus basalis of Meynert in Alzheimer's disease, paralysis agitans, and Korsakoff's disease. Acta Neuropathol (Berl) 1983;61:101-8. 